\title{
Memantine in Behavioral Variant Frontotemporal Dementia: Negative Results
}

\author{
Martine Vercelletto ${ }^{\mathrm{a}, *}$, Claire Boutoleau-Bretonnière ${ }^{\mathrm{a}}$, Christelle Volteau ${ }^{\mathrm{b}}$, Michèle Puel ${ }^{\mathrm{c}}$, \\ Sophie Auriacombe ${ }^{\mathrm{d}}$, Marie Sarazin ${ }^{\mathrm{e}}$, Bernard-François Michel ${ }^{\mathrm{f}}$, Philippe Couratier ${ }^{\mathrm{g}}$, \\ Catherine Thomas-Antérion ${ }^{\mathrm{h}}$, Patrice Verpillat ${ }^{\mathrm{i}}$, Audrey Gabelle ${ }^{\mathrm{j}}$, Véronique Golfier ${ }^{\mathrm{k}}$, \\ Evelyne Cerato ${ }^{\mathrm{b}}$ and Lucette Lacomblez ${ }^{\mathrm{l}}$ \\ ${ }^{\mathrm{a}}$ CMRR, Centre d'investigation Clinique (CIC), Clinique Neurologique, Hôpital R et G Laënnec, \\ Boulevard Jacques Monod, Nantes, France \\ ${ }^{\mathrm{b}}$ Plateforme de Biométrie, CPRC CHU de Nantes, Nantes, France \\ ${ }^{\mathrm{c}}$ CMRR de Toulouse, Clinique Neurologique, Hôpital Purpan, Place du Dr Baylac, Toulouse, France \\ ${ }^{\mathrm{d}}$ CMRR de Bordeaux, Clinique Neurologique, Hôpital Pellegrin, Place A Raba Léon, Bordeaux, France \\ ${ }^{\mathrm{e}}$ CMRR Ile de France, Service de Neurologie, Hôpital de la Salpêtrière, 47-48 Boulevard de l'Hôpital, \\ Paris, France \\ ${ }^{\mathrm{f}}$ Unité de Neurologie, Hôpital Sainte-Marguerite, Marseille, France \\ g CMRR de Limoges, Service de Neurologie, Hôpital Dupuytren, 2 Rue Martin Luther King, Limoges, France \\ ${ }^{\mathrm{h}}$ CMRR de Saint Etienne, Clinique Neurologique, Hôpital Bellevue, 25 Boulevard Pasteur, Saint-Etienne, France \\ i INSERM U 679, Hôpital de la Salpêtrière, 47 Boulevard de l'Hôpital, Paris, France \\ ${ }^{\mathrm{j}}$ CMRR de Montpellier, Hôpital Gui de Chauliac, 80 Avenue A Fliche, 5 Montpellier Cedex, France \\ ${ }^{\mathrm{k}}$ CMRR de Rennes, Hôpital Pontchaillou, 2 Rue Henri Le Guillou, Rennes, France \\ ${ }^{1}$ Fédération des Maladies du Système Nerveux, APHP Hôpital de la Salpêtrière; UPMC Paris VI, \\ Pharmacologie; INSERM U 678, 47-48 Boulevard de l'Hôpital, Paris, France
}

\section{French research network on Frontotemporal dementia}

Martine Vercelletto (CHU Nantes), Michèle Puel (CHU Toulouse), Sophie Auriacombe (CHU Bordeaux), Marie Sarazin (APHP Paris), Bernard-François Michel (CH Sainte Marguerite, Marseille), Philippe Couratier (CHU Limoges), Catherine Thomas-Antérion (CHU Saint-Etienne), Patrice Verpillat (INSERM U 679, APHP Paris), Audrey Gabelle (CHU Montpellier), Véronique Golfier (CHU Rennes), François Sellal (CHU Strasbourg), Lucette Lacomblez (INSERM U 678 APHP Paris).

Accepted 1 November 2010

\begin{abstract}
We tested the efficacy and tolerability of one-year treatment with memantine (10 mg bid) in behavioral variant frontotemporal dementia (bvFTD). BvFTD patients aged 45 to 75 years, with a Mini-Mental Status Examination (MMSE) score $\geq 19$, were enrolled in a national, randomized, double-blind, placebo-controlled (DBPC), Phase II trial. The primary endpoint was the CIBIC-Plus (Clinician's Interview-Based Impression of Change Plus Caregiver Input). The secondary endpoints included: Neuropsychiatric Inventory (NPI), Frontal Behavioral Inventory (FBI), Mattis Dementia Rating Scale (MDRS), MMSE, Disability Assessment for Dementia (DAD), and the Zarit Burden Inventory (ZBI). Forty-nine patients were analyzed. At baseline, mean age was 65.6 years and mean MMSE was 25.0 (range: 19-30). On the CIBIC-Plus, 52 weeks after baseline, there were
\end{abstract}

\footnotetext{
${ }^{*}$ Correspondence to: Martine Vercelletto, Centre Mémoire Recherche et Ressources (CMRR), Centre d'Investigation Clinique (CIC), Clinique Neurologique CHU Nord, 44093 Nantes, France. Tel.: +33 2 40165205; Fax: +33 2 40165397; E-mail: martine. vercelletto@chu-nantes.fr.
} 
no significant differences between the memantine group $(n=23)$ and the placebo group $(n=26) ; p=0.4458$; however, 10 patients had worsened in the memantine group versus 17 in the placebo group. For the secondary endpoints there were no differences in the evolution of score between the memantine group and the placebo group (MMSE, $p=0.63$ ); (MDRS, $p=0.95$ ); (NPI, $p=0.25$ ); (ZBI, $p=0.43$ ); (DAD, $p=0.10$ ) except for the FBI score, which was lower in the memantine group $(p=0.0417)$. Memantine was well-tolerated. This is the first DBPC trial in a large group of bvFTD patients involving neuroprotective treatment. A multinational study with a larger number of patients is now needed in order to verify the results of our study. The trial is registered with ClinicalTrials.gov; number NCT 00200538.

Keywords: Behavioral variant frontotemporal dementia, double-blind placebo-controlled trial, memantine

\section{INTRODUCTION}

Behavioral variant of frontotemporal dementia (bvFTD) represents $75 \%$ of cases of frontotemporal lobar degeneration (FTLD). The diagnostic criteria for bvFTD are well-established yet [1]. This rare form of dementia, affecting young subjects, with onset usually before the age of 60 years (mean 58 years), is one of the main causes of presenile dementia and evolves faster than AD, leading to death [2]. There are no Food and Drug Administration (FDA) approved medications indicated for the treatment of bvFTD, whereas therapeutic research in the field of Alzheimer's disease (AD) is developing rapidly.

Memantine, a drug widely used for the management of $\mathrm{AD}$, is also likely to be relevant in bvFTD. Memantine is a moderate-affinity uncompetitive antagonist of the N-Methyl-D-aspartate (NMDA) ionotropic glutamate receptors. It facilitates physiological glutamate mediated transmission, protects neurons against glutamatergic neuronal transmission, and prevents the toxic effect of the excitatory neurotransmitter glutamate. Although the pathogenic mechanisms underlying FTD are not known, there is some evidence that glutamate toxicity may contribute to neuronal damage in FTD. Memantine could therefore be of interest for the management of this disease. First, changes of expression of both amino-hydroxylmethyl-isoxazole-propionic-acid (AMPA) and NMDA ionotropic glutamate receptors have been shown in the temporal and frontal cortices of bvFTD patients [3]. Second, impaired glutamate transport has been described in a mouse model of tauopathy [4]. Third, memantine is capable of reducing the pathological hyperphosphorylation of tau in vitro [5] and in vivo [6]. We therefore postulated that memantine could be an effective treatment for bvFTD through either a symp- tomatic or a disease-modifying effect. Since 2005, four open-label therapeutic trials with memantine in bvFTD have been published. Some of them included temporal variant of FTD (tvFTD). The small study by Swanberg [7] $(n=3)$ demonstrated an improvement in neuropsychiatry inventory (NPI) score [8] (for apathy, agitation and anxiety) after 3 months. The study by Sharre [9] included 10 patients treated for 6 months. No changes were observed in terms of cognition (Alzheimer Disease Assessment Scale - Cognition ADAS-Cog), behavior (total NPI), Activities of Daily Living and Clinical Dementia Rating (CDR) scale. The study by Diehl-Schmid et al. [10] conducted in a single centre, included 16 patients ( 9 bvDFT and 7 tvDFT) treated with $10 \mathrm{mg}$ bid memantine for 6 months. On the main outcome measure Clinician's Interview-Based Impression of Change with caregiver Input (CIBIC-Plus) [11], 4 patients were minimally improved, 4 patients were unchanged, 7 patients were minimally worse, and one patient was moderately worse. The study by Boxer et al. [12], carried out for 6 months with $20 \mathrm{mg}$ memantine, also included the three subtypes of FTD: 21 patients with bvFTD, 13 with semantic dementia and 9 with non fluent progressive aphasia. The MMSE at baseline was 22/30. On the behavioral scales, the authors noted a transitory improvement on the NPI at week 16 and then a decline at week 26 in the bvFTD group. No differences were noted on any of the other behavioral and cognitive scales between the baseline visit and the visit at 6 months. To date no published data from controlled trials with memantine in FTD are available.

The aim of our study is to assess the efficacy and tolerability of one-year treatment with memantine in patients with bvFTD in a double-blind placebocontrolled (DBPC) trial with the FDA-approved dose 
for $\mathrm{AD}$ [13]. The primary objective was to demonstrate the efficacy of memantine based on the overall global change relative to baseline (primary endpoint) and the rate of decline in secondary endpoints.

\section{METHODS}

\section{Patients and treatment}

Ambulatory patients of either gender presenting Neary's five criteria [1] for bvFTD and aged between 45 and 75 years were included between September 2006 and June 2008 in a national, randomized, multicenter, parallel group, DBPC, Phase II therapeutic trial. Patients were recruited from 10 centers in the French FTD network (Nantes, Toulouse, Bordeaux, Paris, Marseille, Limoges, Saint-Etienne, Montpellier, Rennes, and Strasbourg). To be included in the study, patients were required to have bvFTD, evolving for at least 1 year, a Mini Mental Status Examination (MMSE) [14] score $\geq 19$, a Frontotemporal Behavioral Scale [15] score $>3$, and a Montgomery Depression Assessment Rating Scale (MADRS) [16] score $<20$. All patients underwent magnetic resonance imaging (MRI) or cranial computed tomography scan, to exclude focal lesion, and single photon emission computed tomography (SPECT). Any psychotropic treatment had to have been stable for the previous 3 months. All patients had to have given written informed consent and had to be accompanied by a reliable caregiver who could provide information about the patient. Patients with the tvFTD (semantic dementia or progressive non-fluent aphasia) or motoneuron disease involvement and patients treated with an acetylcholinesterase inhibitor were excluded.

\section{Procedures}

Patients were randomly allocated to treatment, using a list of random numbers, with a memantine to placebo ratio of $1: 1$. Memantine $(10 \mathrm{mg})$ and placebo were prepared as identical tablets (HLundbeck A/S). Packaging and labeling ( $\mathrm{LC}^{2}$, Lentilly-France) and treatment management were performed so as to safeguard blinding to treatment allocation throughout the duration of the trial. On receipt of a faxed notification of a patient's inclusion in the study, the appropriate treatment was sent to the pharmacy department of the center concerned. Patients received either memantine $(10 \mathrm{mg}$ bid), initiated gradually during the first 3 weeks, or placebo, twice daily. All study personnel and partic- ipants were blinded to treatment assignment for the duration of the study.

\section{Assessment}

The primary endpoint was defined as a global change during the 1-year double-blind period of the study as assessed by the CIBIC-Plus [11]. For the CIBIC-Plus, a clinician unaware of all assessments and other aspects of the trial carried out a semistructured interview with the patient and caregiver, exploring four areas: general condition, cognitive function, behavior, and activities of daily living. Each of the four areas was subdivided into domains that were assessed with probes. The overall severity at baseline (Clinician's Interview-based Impression of Severity [CIBIS]) was rated on a 7-point scale from 'extremely severe' to 'no symptoms of disease', and the overall global change relative to baseline (CIBIC-Plus) was scored on a seven-point scale ranging from 1 (markedly improved) to 7 (markedly worse). Experienced clinicians, blinded to adverse events and other study assessments, conducted separate interviews with study patients and their caregivers to assess overall change on the CIBIC-Plus. To ensure consistency, the same clinician in each centre completed all CIBIC-Plus interviews for each study patient and associated caregiver. There were three assessors: the principal investigator, a CIBIC-Plus rater and a neuropsychologist.

Secondary endpoints included behavioral scales: Neuropsychiatric Inventory (NPI) [8] and Frontal Behavioral Inventory (FBI) [17]; global cognitive scales: MMSE and Mattis Dementia Rating Scale (MDRS) [18]; evaluation of activities of daily living using the Disability Assessment Daily (DAD) [19]; evaluation of the burden using the Zarit Burden Inventory (ZBI) [20].

The screening visit was performed between 7 and a maximum of 21 days before randomization. Randomization indicated the time M0 (Month 0). CIBIS and secondary endpoints were performed at M0. Patients had one visit per month during the first 3 months, then every 3 months. CIBIC-Plus and all secondary endpoint measures were assessed every 3 months (M3, M6, M9, M12) for 12 months.

Memantine safety was assessed by monitoring at each visit by recording adverse events, physical and neurological examination results vital signs and routine laboratory values (creatinaemia, complete blood count, platelets, ASAT/ALAT) taken at inclusion and after 3 and 12 months of treatment. 


\section{Sample size}

We estimated the sample size for the study with data from Reisberg's memantine study [13]. Our hypothesis was to obtain a difference of $0.65 \pm 1.09$ in CIBIC-Plus score between the two groups. However, to be able to demonstrate a difference of this magnitude with an alpha risk of 5\% (two-sided) and a power of $80 \%$, we would have required 45 patients per group, a figure that was not immediately feasible given the difficulty of recruitment. We estimated that it should be possible to recruit 64 patients within 18 months, given the recruitment potential of the various centers in the French FTD network.

\section{Statistical analysis}

The main analysis for primary and secondary endpoints compared change from baseline for the memantine group versus the placebo group and was based on the intention-to-treat (ITT) population. The ITT population was defined as all randomized patients who received at least one dose of study medication, at least one clinical assessment. The comparison between the memantine and placebo groups at baseline was carried out for the following criteria: disease severity (CIBIS), age, disease duration, gender, years of education, and cognitive and behavioral disturbances (secondary endpoints). Comparisons were done with the Chi-square test for qualitative variables and the Wilcoxon-Mann-Whitney test for quantitative variables.

For the primary endpoint (CIBIC-Plus), missing data was replaced in both groups by the worst value ("substantial worsening"). CIBIC-Plus was compared by Wilcoxon-Mann-Whitney test. Three additional sensitivity analyses were also performed to cross check the missing values. First, missing data were imputed by placebo group mean. Next, for the memantine and the placebo group missing data were imputed using the most recent previous observation (LOCF: Last Observation Carried Forward). The third analysis was performed in patients who had an evaluation at M12. Adjustment for disease severity was performed with a mixed linear model. A Random effect linear regression model (with random slope and random intercept) was used to compare the evolution of CIBIC-Plus between randomization (CIBIS) and M12. Interaction between time and group was tested.

For the secondary endpoints (MMSE, MDRS, NPI, FBI, DAD, and ZBI), differences between the score at $\mathrm{M} 12$ and the score at M0 were calculated and compared between the two arms using Wilcoxon-Mann-Whitney tests. Random effect linear regression models were used to compare the evolution of the secondary criteria. Fixed effects were group, time, interaction between group and time and baseline value. There was no imputation of missing data for the secondary endpoints. The safety population comprised all randomized patients who received at least one dose of study medication.

We assumed an alpha risk of 5\%. Statistical analyses were performed using SAS $^{\circledR}$ version 9.1 (SAS Institute, Cary, NC, USA).

\section{Ethics}

The study was approved by the local ethics committee CCP (Comité de Protection des Personnes), Nantes.

\section{RESULTS}

\section{Study population}

Figure 1 shows the trial profile. Fifty-two patients were randomly assigned. Three patients in the memantine group did not receive treatment, so they were not evaluated and were therefore excluded from all analyses. The ITT population was 49 (memantine group $n=23$; placebo group $n=26$ ). Eight additional patients dropped out of the study: five in the memantine group (one patient suffered worsening of semantic dementia and dropped out at 3 months, 2 patients died [at M4 and M5], one patient withdrew consent, and one patient was withdrawn by decision of the investigator at M6) and three in the placebo group (2 were withdrawn by decision of investigator [at M6 and M11] and 1 patient withdrew due to a severe pathology [renal insufficiency] at M3).

After blinded review of all inclusion criteria by the steering committee two protocol deviations were accepted: a 76-year-old patient at baseline and a patient with a secondary diagnosis of semantic dementia. Moreover, at baseline, $82 \%(n=40)$ of the 49 patients fulfilled the five criteria of Neary and $18 \%(n=9)$ fulfilled only three or four of these criteria. Nevertheless, all patients included had a score $>3$ on the Frontotemporal Behavioral Scale [15]. This deviation from the protocol was accepted insofar as it frequently occurs that at the first consultation not all of the five criteria are fulfilled. Medication compliance exceeded $98 \%$ in both groups.

The baseline characteristics were similar in the two groups (Table 1). All patients were Caucasian. The 


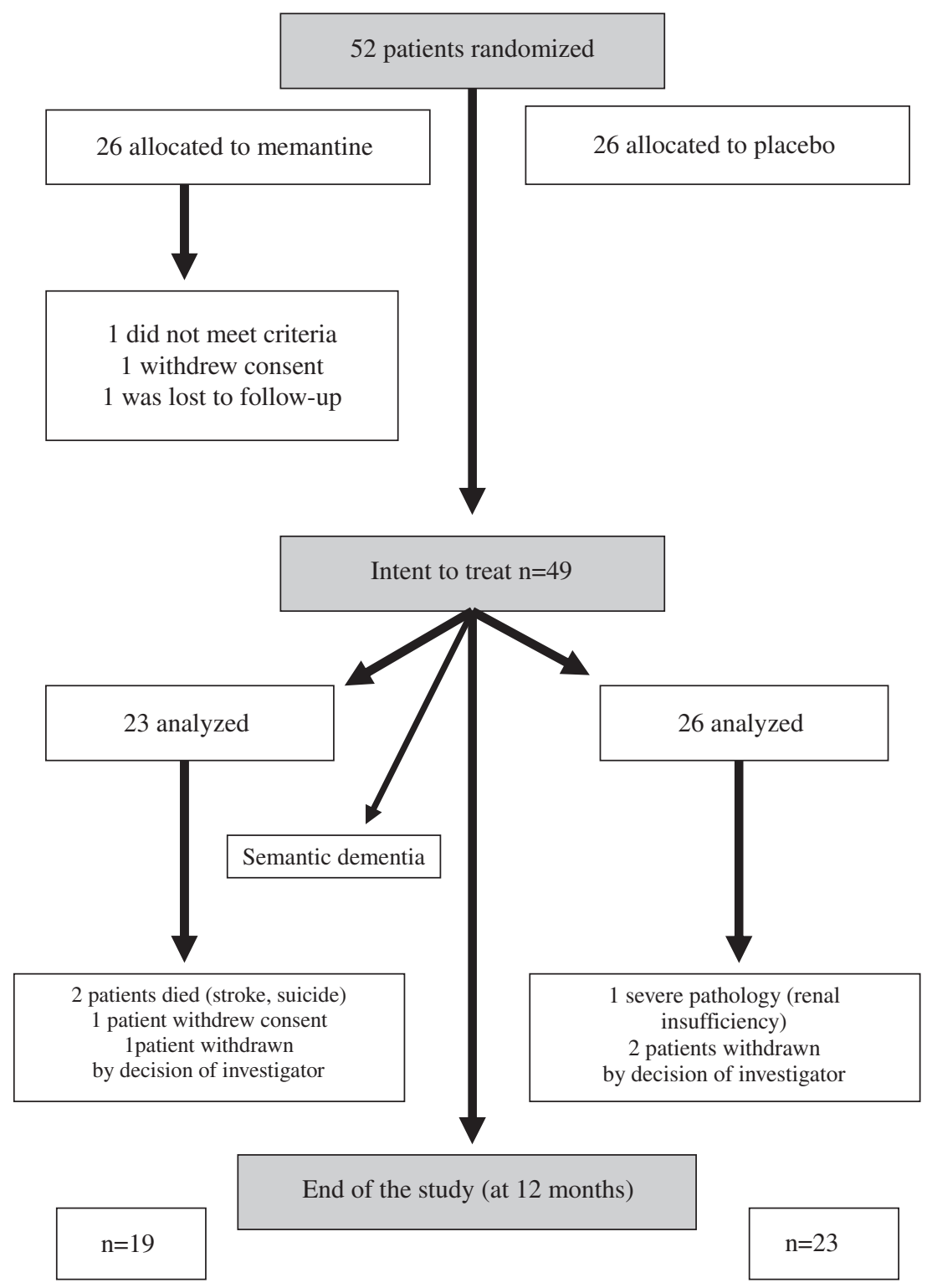

Fig. 1. Trial profile.

memantine and placebo groups were comparable in terms of age, level of education, disease duration, MMSE score, Frontal Assessment Battery (FAB) [21], disease severity (CIBIS), behavioral and cognitive state, activities of daily living, and burden.

\section{Efficacy}

\section{Primary endpoint}

At 52 weeks, after the imputation of missing data with the worst value, there were no statistically sig- nificant differences on the CIBIC-Plus between the memantine group and the placebo group, $p=0.4458$ (Table 2). This was confirmed by repeated measure analysis (Table 3), which showed that the change on the CIBIC-Plus between M0 and M12 was not significantly different between the two groups. The conclusion remained the same with the sensitivity analysis (Table 3). With the qualitative analysis only 10 patients had worsened in the memantine group versus 17 in the placebo group, though the difference did not reach statistical significance $(p=0.142)$ (Table 4 , Fig. 2). 
Table 1

Baseline characteristics for both groups $(n=49)$

\begin{tabular}{lcccc}
\hline & $\begin{array}{c}\text { Memantine } \\
(n=23)\end{array}$ & $\begin{array}{c}\text { Placebo } \\
(n=26)\end{array}$ & $\begin{array}{c}\text { Total } \\
(n=49)\end{array}$ & $p$-value \\
\hline Age (years) & $64.4(7.5)$ & $66.6(7.4)$ & $65.6(7.4)$ & 0.4099 \\
Men (\%) & $15(65.2)$ & $16(61.5)$ & $31(63.3)$ & 0.7898 \\
Education (years) & $9.6(4.2)$ & $8.1(3.8)$ & $8.8(4.0)$ & 0.2624 \\
Duration of symptoms (years) & $4.3(2.8)$ & $4.7(3.6)$ & $4.5(3.3)$ & 0.8014 \\
MMSE score & $25.3(3.4)$ & $24.5(3.0)$ & $24.8(3.2)$ & 0.3478 \\
FAB & $11.6(3.8)$ & $11.4(4.0)$ & $11.5(3.8)$ & 0.9840 \\
CIBIS & $4.3(1)$ & $4.7(1.1)$ & $4.5(1)$ & 0.1642 \\
MDRS & $115.4(23.5)$ & $113.5(18.9)$ & $114.4(20.9)$ & 0.3778 \\
NPI & $27.7(11.4)$ & $31.1(19.6)$ & $29.5(16.2)$ & 0.7498 \\
FBI & $26.6(8.6)$ & $27.8(11.1)$ & $27.2(10)$ & 0.8031 \\
DAD & $65.7(19)$ & $58.3(27.8)$ & $61.8(24.1)$ & 0.4802 \\
ZBI & $42.0(16.5)$ & $34.46(17.1)$ & $38.0(17.0)$ & 0.1511 \\
\hline
\end{tabular}

Data are mean (SD); Wilcoxon-Mann-Whitney test/Chi-square test.

Table 2

Results of the analysis of the primary endpoint (CIBIC-Plus)

\begin{tabular}{|c|c|c|c|c|}
\hline & $\begin{array}{l}\text { Memantine } \\
(n=23)\end{array}$ & $\begin{array}{l}\text { Placebo } \\
(n=26)\end{array}$ & $\begin{array}{c}\text { Difference }[95 \% \text { IC] } \\
\text { Memantine - Placebo }\end{array}$ & $p$-value* \\
\hline \multicolumn{5}{|c|}{ Without imputation of missing data } \\
\hline$n$ & 18 & 23 & & \\
\hline Mean (SD) & $4.4(1.7)$ & $5.2(1.6)$ & $-0.8[-1.8 ; 0.2]$ & 0.1098 \\
\hline Median (interquartile range) & $5(3 ; 5)$ & $6(4 ; 6)$ & & \\
\hline \multicolumn{5}{|c|}{ Missing data replaced by the worst value } \\
\hline$n$ & 23 & 26 & & \\
\hline Mean (SD) & $5.0(1.8)$ & $5.4(1.6)$ & $-0.43[-1.40 ; 0.55]$ & 0.4458 \\
\hline Median (interquartile range) & $5(3 ; 7)$ & $6(5 ; 7)$ & & \\
\hline \multicolumn{5}{|c|}{ Missing data replaced by placebo group mean } \\
\hline$n$ & 23 & 26 & & \\
\hline Mean (SD) & $4.6(1.5)$ & $5.2(1.5)$ & $-0.61[-1.46 ; 0.15]$ & 0.1173 \\
\hline Median (interquartile range) & $5.0(3 ; 5)$ & $5.2(5 ; 6)$ & & \\
\hline \multicolumn{5}{|l|}{ Missing data replaced by LOCF } \\
\hline$n$ & 22 & 26 & & \\
\hline Mean (SD) & $4.5(1.5)$ & $5.3(1.6)$ & $-0.77[-1.67 ; 0.14]$ & 0.0724 \\
\hline Median (interquartile range) & $5(3 ; 5)$ & $6(4 ; 6)$ & & \\
\hline
\end{tabular}

Table 3

Evolution of the CIBIC-Plus between 3 and 12 months - linear mixed model -49 patients

\begin{tabular}{|c|c|c|c|c|}
\hline & Estimate & $\begin{array}{c}\text { Standard } \\
\text { error }\end{array}$ & $95 \%$ IC & $\overline{p \text {-value }}$ \\
\hline Intercept & 4.23 & 0.27 & {$[3.68 ; 4.78]$} & $<0.0001$ \\
\hline $\begin{array}{r}\text { Group (reference: } \\
\text { Placebo group) }\end{array}$ & -0.14 & 0.38 & {$[-0.90 ; 0.61]$} & 0.7041 \\
\hline Time & 0.07 & 0.02 & {$[0.02 ; 0.12]$} & 0.0077 \\
\hline
\end{tabular}

Table 4

Qualitative analysis of the CIBIC-Plus (number and percentage)

\begin{tabular}{lccc}
\hline & $\begin{array}{c}\text { Memantine } \\
(n=23)\end{array}$ & $\begin{array}{c}\text { Placebo } \\
(n=26)\end{array}$ & $p$-value* \\
\hline Improved & $6(33.3)$ & $3(13.0)$ & 0.1428 \\
Stable & $2(11.1)$ & $3(13.0)$ & \\
Worsened & $10(55.6)$ & $17(73.9)$ & \\
\hline
\end{tabular}

For the secondary endpoints, there was no statistically significant difference between the two groups at 52 weeks compared to baseline on any of the scales (Table 5 ). Furthermore, the secondary endpoints evolved in a similar manner in the two groups; the interactions between time and arm were not significant (MMSE, $p=0.63$; MDRS, $p=0.95$; NPI, $p=0.25$; ZBI, $p=0.43$; DAD, $p=0.10$ ), except for the FBI $(p=0.0417)$ (Table 6). The mean score on the FBI increased more quickly in the placebo group than in the memantine group (Table 6, Fig. 3 ).

\section{Safety and tolerability}

There were no medically significant changes in laboratory parameters during the study and no difference was found between the two groups. Six (26\%) of the 


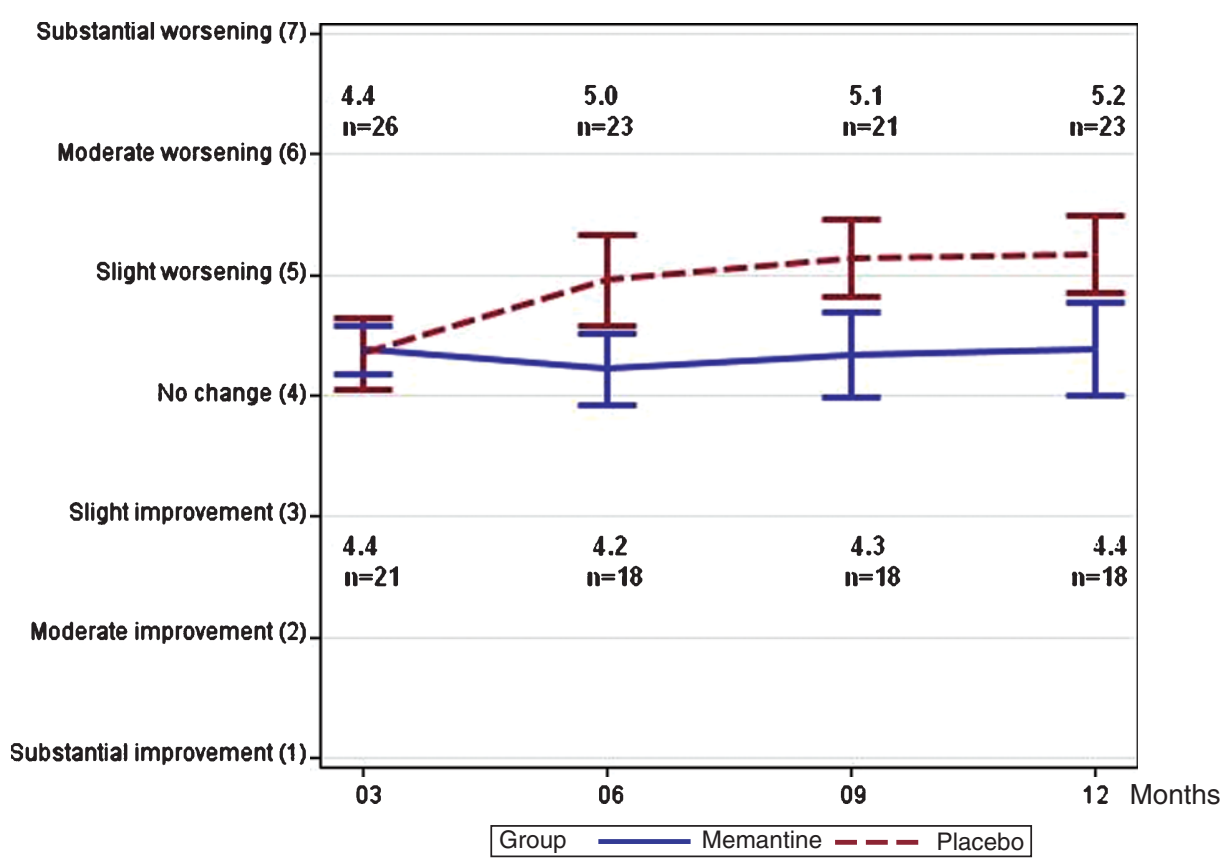

Fig. 2. Graphic presentation of the CIBIC-Plus (mean value).

Table 5

Results of the analysis of the secondary endpoints

\begin{tabular}{|c|c|c|c|c|c|}
\hline & \multicolumn{2}{|c|}{ Memantine $(n=23)$} & \multicolumn{2}{|c|}{ Placebo $(n=26)$} & \multirow[t]{2}{*}{$p$-value ${ }^{\#}$} \\
\hline & Baseline* & Difference at 12 months $* *$ & Baseline & Difference at 12 months & \\
\hline MMSE/30* & $\begin{array}{c}25.3 \pm 3.4 \\
26 \\
(n=23)\end{array}$ & $\begin{array}{c}-3.2 \pm 5.5[-5.9 ;-0.6] \\
-2(-6 ; 1) \\
(n=19)\end{array}$ & $\begin{array}{c}24.5 \pm 3.0 \\
24 \\
(n=26)\end{array}$ & $\begin{array}{c}-5.0 \pm 5.1[-7.3 ;-2.7] \\
-4(-10 ;-1) \\
(n=22)\end{array}$ & 0.2719 \\
\hline MDRS/144 & $\begin{array}{c}115.4 \pm 23.5 \\
120.5 \\
(n=22)\end{array}$ & $\begin{array}{c}-8.2 \pm 19.1[-18.4 ; 2.0] \\
-0.5(-16 ; 6.5) \\
(n=16)\end{array}$ & $\begin{array}{c}113.5 \pm 18.9 \\
114 \\
(n=26)\end{array}$ & $\begin{array}{c}-14.5 \pm 30.6[-28.1 ;-0.9] \\
-4.5(-33 ; 3) \\
(n=22)\end{array}$ & 0.3965 \\
\hline NPI/144 & $\begin{array}{c}27.7 \pm 11.4 \\
26 \\
(n=23)\end{array}$ & $\begin{array}{c}1.9 \pm 13.8[-5.2 ; 9.0] \\
3(-8 ; 10) \\
(n=17)\end{array}$ & $\begin{array}{c}31.1 \pm 19.6 \\
25.5 \\
(n=26)\end{array}$ & $\begin{array}{c}7.4 \pm 15.1[0.7 ; 14.0] \\
8(-3 ; 17) \\
(n=22)\end{array}$ & 0.2098 \\
\hline FBI/72 & $\begin{array}{c}26.6 \pm 8.6 \\
27 \\
(n=23)\end{array}$ & $\begin{array}{c}3.7 \pm 7.3[-0.1 ; 7.5] \\
4(1 ; 9) \\
(n=17)\end{array}$ & $\begin{array}{c}27.8 \pm 11.2 \\
27.5 \\
(n=26)\end{array}$ & $\begin{array}{c}8.3 \pm 10.0[3.9 ; 12.7] \\
5.5(3 ; 16) \\
(n=22)\end{array}$ & 0.1236 \\
\hline $\mathrm{ZBI} / 88$ & $\begin{array}{c}42.0 \pm 16.5 \\
44.5 \\
(n=22)\end{array}$ & $\begin{array}{c}6.1 \pm 12.8[-0.7 ; 12.9] \\
6.5(-1.5 ; 16) \\
(n=16)\end{array}$ & $\begin{array}{c}34.6 \pm 17.1 \\
34.5 \\
(n=26)\end{array}$ & $\begin{array}{c}11.5 \pm 16.2[4.5 ; 18.5] \\
14(-2 ; 20) \\
(n=23)\end{array}$ & 0.3444 \\
\hline DAD (\% YES) & $\begin{array}{c}65.7 \pm 19.0 \\
66.7 \\
(n=23) \\
\end{array}$ & $\begin{array}{c}-7.4 \pm 16.5[-15.9 ; 1.1] \\
-7.4(-15.2 ; 0) \\
(n=17)\end{array}$ & $\begin{array}{c}58.3 \pm 27.8 \\
64.1 \\
(n=26)\end{array}$ & $\begin{array}{c}-19.5 \pm 26.3[-31.2 ;-7.8] \\
-18.3(-41 ;-2.5) \\
(n=22)\end{array}$ & 0.1029 \\
\hline
\end{tabular}

$*$ Mean \pm SD; Median; number of subjects; **Mean difference \pm SD $\left[95 \%\right.$ IC]; median (interquartile range); ${ }^{*}$ Wilcoxon-Mann-Whitney tests.

23 patients in the memantine group and eight $(31 \%)$ of the 26 patients in the placebo group presented a serious adverse event (SAE) (Table 7). Three patients in the placebo group and three patients in memantine group (including two deaths) dropped out due to an SAE.
Thirty-five percent $(n=8)$ of patients in the memantine group experienced a combined total of 12 adverse events (AE) (lumbago, institutionalization, loss of consciousness, vertigo, arthrosis, constipation, insomnia, agitation, cutaneous lesion, dislocation, bronchitis, thumb pain); $39 \%(n=10)$ of patients in the placebo 
Table 6

Evolution of the FBI between 3 and 12 months - Linear mixed model - 49 patients

\begin{tabular}{lcccr}
\hline & Estimate & $\begin{array}{c}\text { Standard } \\
\text { error }\end{array}$ & IC 95\% & $p$-value \\
\hline Intercept & 6.88 & 3.82 & {$[-0.80 ; 14.6]$} & \\
Group (reference: & 3.57 & 2.67 & {$[-1.75 ; 8.88]$} & 0.1853 \\
$\quad$ Placebo group) & 0.81 & 0.18 & {$[0.45 ; 1.17]$} & 0.0003 \\
Time & -0.56 & 0.27 & {$[-1.09 ;-0.02]$} & 0.0417 \\
Interaction group $\times$ time & 0.65 & 0.12 & {$[0.40 ; 0.89]$} & $<0.0001$ \\
FBI at baseline & 0.81 & 0.18 & {$[0.45 ; 1.16]$} & \\
Slope group placebo & 0.25 & 0.20 & {$[-0.15 ; 0.65]$} & \\
Slope group memantine & 0.56 & 0.27 & {$[0.02 ; 1.09]$} & \\
Placebo - Memantine & & & &
\end{tabular}

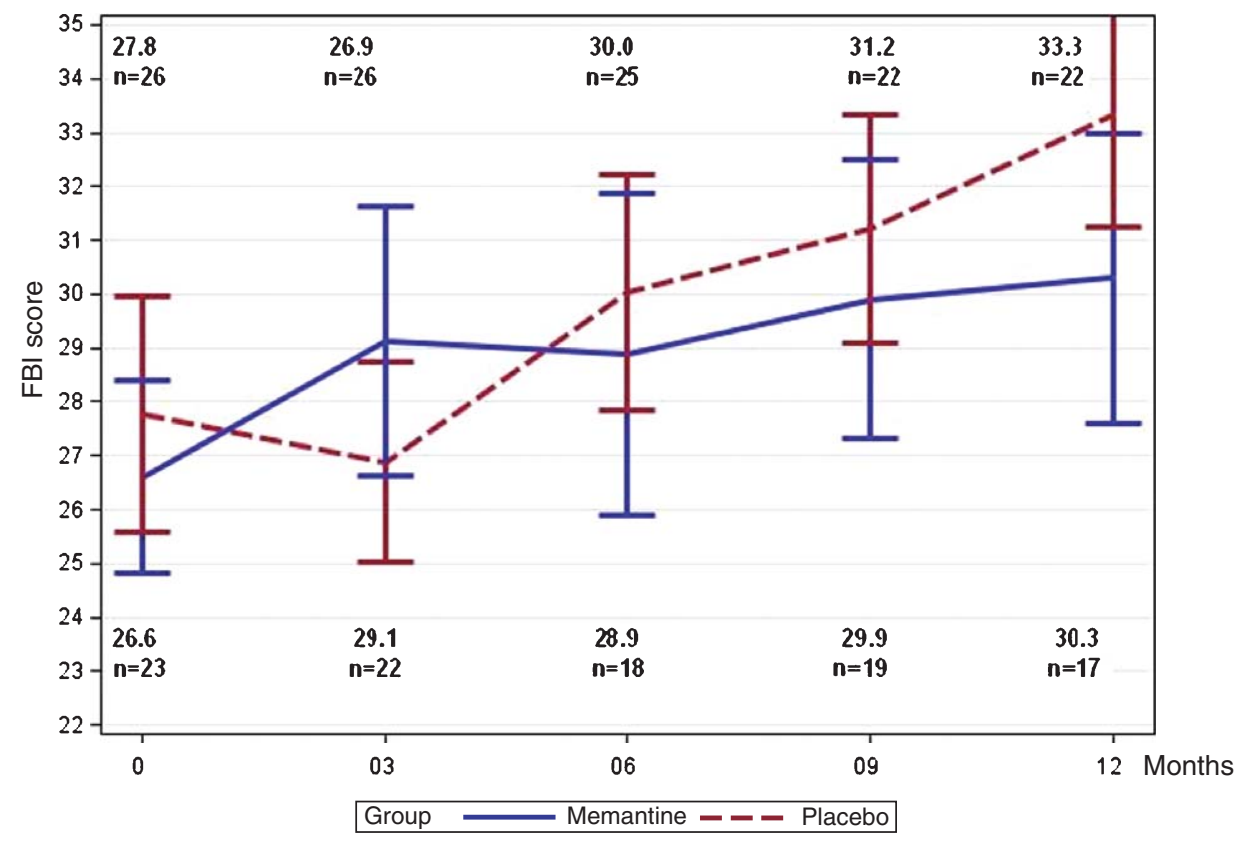

Fig. 3. Graphic presentation of the FBI (mean value).

Table 7

Serious adverse events (SAE)

\begin{tabular}{ll}
\hline $\begin{array}{l}\text { Memantine group } \\
(n=23)\end{array}$ & Placebo group $(n=26)$ \\
\hline $\begin{array}{l}\text { Psychomotor agitation* } \\
\text { Suicide* }\end{array}$ & $\begin{array}{l}\text { Acute renal insufficiency* } \\
\text { Worsening of behavioural disturbances }\end{array}$ \\
Stroke resulting in death* & $\begin{array}{l}\text { Pulmonary embolism } \\
\text { Institutionalization }\end{array}$ \\
Erythrodermia* \\
Pulmonary embolism & Malaise with loss of consciousness \\
& Urticaria* \\
& Pneumopathy \\
& Cutaneous adenocarcinoma \\
\hline
\end{tabular}

*Dropped out as a result.

group experienced a total of $24 \mathrm{AE}$ (constipation, high blood pressure, headaches $[n=3]$, neurological deterioration, agitation, diarrhea [ $n=2]$, falls $[n=2]$, vertigo, insomnia, cramp in the calves, delirium, influenza, cutaneous erythema, rhinitis, allergy, eczema, gastroesophageal reflux, diabetes, urinary infection, fracture of the shoulder). There were no treatment withdrawals or drop-outs related to AE.

\section{DISCUSSION}

This national multicenter study, in which 49 patients were followed up for 12 months, is the first DBPC study with memantine in bvFTD. The generalizability of the trial is good because the secondary endpoints are performed in clinical practice. We included only bvFTD, which are the most frequent and most homogeneous, since there is no language disturbance. We found that memantine was well-tolerated. On the qualitative analysis of the CIBIC-plus, only 10 patients worsened in 
memantine group versus 17 in the placebo group. Of particular interest is the finding of a lower score on the FBI in memantine group $(p=0.0417)$. The FBI has high sensitivity in the assessment of behavioral symptoms for bvFTD and is sensitive to change in personality [22]. But the results on the CIBIC-Plus, and on the secondary endpoints were not statistically significant. So memantine did not improve bvFTD.

The results of our study cannot be directly compared with those of selective serotonin reuptake inhibitor (SSRI) trials. Indeed it has been shown that patients with bvFTD have deficiencies in the serotonin neurotransmitter system [23]. SSRI therapeutic trials aimed at treating the behavioral disturbances that characterize this disease have been carried out. Since the study by Swartz and coworkers [24], only two DBPC studies evaluating the effect of a SSRI on behavioral disorders have been published $[25,26]$. No improvement was observed after 6 weeks in the group treated with paroxetine compared to the placebo group [24]. Trazodone (5 HT2A antagonist) and SSRIs led to a behavioral improvement, with a 50\% reduction in the NPI score in 10 patients [26]. A meta-analysis of the effects of SSRIs and trazodone on the NPI [23] in FTD demonstrated a mean reduction (i.e., an improvement) of 15.4 points in bvFTD, supporting the use of these drugs as first-line agents for the management of behavioral symptoms in FTD. The studies on SSRIs did not use the same methodology as our study nor was the level of severity the same. Furthermore, the number of patients included was small (a maximum of 26). Apart from SSRIs, open-label therapeutic trials focusing on cognitive functions and using agents such as presynaptic adrenergic $\alpha 2$ or noradrenergic $\alpha 2$ agonists have been carried out in a small number of patients but proved negative [27, 28]. Two studies used acetylcholinesterase inhibitors, even though there is no cholinergic deficit in bvFTD. The DBPC study by Mendez et al. [29] gave negative results.

The number of cases included in memantine openlabel trials [7, 9, 10, 12] or in SSRRs trial illustrates the difficulty of recruitment. Effectively the main limitation of our study concerns the number of patients. The difficulty of recruitment can be explained by the rarity of the disease and the restrictive inclusion criteria. We chose mild bvFTD with an MMSE score $>19$. In 18 months we succeeded in analyzing 49 cases of bvFTD. As this was the first study of its kind in France it was difficult to estimate the capacity for recruitment. The study could not be extended in time due to the expiry date of the drugs. This was therefore an academic study. The other limitations on our study concern the speci- ficity of Neary's criteria and the choice of assessment scales. The lack of specificity of Neary's criteria in the early stage of FTD has been confirmed [30], since only $56 \%$ of bvFTD patients in their study fulfilled all five of Neary's criteria at the initial consultation (mean MMSE score 24). In our study, at the inclusion visit, $82 \%(n=40)$ of the 49 patients fulfilled all five of Neary's criteria.

In 2005 and at present, the choice of scales to assess treatment for bvFTD had not yet been codified. Since we were unaware of whether memantine would act upon cognition or behavior in bvFTD, we chose a global scale, the CIBIC-Plus, which is already used in clinical trials in $\mathrm{AD}$, and was previously used [13] in a memantine trial with AD patients. Knopman et al. [31] looked at methods of evaluating FTD in the event of a therapeutic trial being carried out in this disease. They proposed using the NPI and the FBI on a behavioral level, the ADAS-Cog on a cognitive level, and the Functional Assessment Questionnaire (FAQ) for activities of daily living. The CDR scale modified for frontal pathologies (CDR-FTD) would appear to be a useful tool for a global assessment but is not currently available in France. The choice of scales may also be influenced by the stage of the disease. Our study involved early stage bvFTD patients (mean MMSE score: 25), whereas in other studies, with psychotropic treatments, the patients presented more severe cognitive disturbances, such as in the study with trazodone [26] (mean MMSE score: 9.5; $n=26$ ). Moreover, the natural course of the disease is still unclear. The mean annual decline on various tests in a large sample of patients is still unknown.

Memantine would appear to be a potential treatment for bvFTD, but a further study with a larger number of cases will be needed to confirm its effect. The molecular, biochemical, genetic, and neuropathological heterogeneity of bvFTD makes it difficult to carry out a therapeutic trial based on a same neuroprotective molecule. In the near future, with a better understanding of the pathogenic pathways involving microtubule-associated protein tau, progranulin, and TDP-43 protein (TAR-DNA binding protein), perhaps other potential disease modifying therapies could be considered [32].

\section{CONCLUSION}

This is the first DBPC study of memantine in bvFTD, with 49 cases being followed up for 12 months. For the primary end point, the qualitative results show that 
more patients worsened in the placebo group than in the memantine group, but the difference does not reach statistical significance. Memantine ( $10 \mathrm{mg}$ bid) appears to be safe and was well-tolerated in these patients but does not improve bvFTD in our study. Nevertheless controlled clinical trials with a larger number of patients, and if necessary multinational studies, should therefore be carried out.

\section{ACKNOWLEDGMENTS}

We thank Dr Jean Michel Nguyen for his contribution to the design of the study and Dr François Sellal for his assistance with inclusion of patient. We thank Dr François Menard (H. Lundbeck S/A) for presenting this project as an Investigator Initiated Trial (ITT) to the Lundbeck Scientific Research Committee in 2004. We thank the staff of the Clinical Investigation Centres of Nantes, Paris (Pitié-Salpêtrière), Bordeaux, Limoges, and Toulouse hospitals. We also thank all the patients who took part in the study.

This study was supported by the Regional Research Grant (PHRC 2004, Pays de Loire, France) No. 20-6; Promoter: Nantes University Hospital. Research grant: H. Lundbeck A/S, Copenhagen, Denmark. Lundbeck was not involved in study design, analysis and interpretation of data, writing the report, or the decision to submit the report for publication. Lundbeck provided memantine and placebo.

The trial is registered with ClinicalTrials.gov; number NCT 00200538.

Authors' disclosures available online (http://www.jalz.com/disclosures/view.php?id=667).

\section{REFERENCES}

[1] Neary D, Snowden JS, Gustafson L, Passant U, Stuss D, Black S, Freedman M, Kertesz A, Robert PH, Albert M, Boone K, Miller BL, Cummings J, Benson DF (1998) Frontotemporal lobar degeneration: a consensus on clinical diagnostic criteria. Neurology 51, 1546-1554.

[2] Hodges JR, Davies R, Xuereb J, Kril J, Halliday G (2003) Survival in frontotemporal dementia. Neurology 61, 349-354.

[3] Procter A, Qurne M, Francis P (1999) Neurochemical features of frontotemporal dementia. Dement Geriatr Cogn Disord 10(suppl. 1), S1615-S1621.

[4] Dabir DV, Robinson MB, Swanson E, Zhang B, Trojanowski JQ, Lee VM, Forman MS (2006) Impaired glutamate transport in a mouse model of tau pathology in astrocytes. $J$ Neurosci 11, 644-654.

[5] Liang Li, Sengupta A, Haque N, Grundke-Iqbal I, Iqbal K (2004) Memantine inhibits and reverse the Alzheimer type abnormal hyperphosphorylation of tau and associated neurodegeneration. FEBS Lett 566, 261-269.
[6] Degerman Gunnarsson M, Kilander L, Basun H, Lannfelt L (2007) Reduction of phosphorylated tau during memantine treatment of Alzheimer's disease. Dement Geriatr Cogn Disord 24, 247-252.

[7] Swanberg MM (2007) Memantine for behavioral disturbances in frontotemporal dementia: a case series. Alzheimer Dis Assoc Disord 21, 164-166.

[8] Cummings JL, Mega M, Gray K, Rosenberg-Thompson S, Carusi DA, Gornbein J (1994) The neuropsychiatric inventory: comprehensive assessment of psychopathology in dementia. Neurology 44, 2308-2314.

[9] Sharre WD, Warner JL, Davis RA, Theado-Miller N (2005) Memantine in frontotemporal dementia. Neurology 64, P02 077.

[10] Diehl-Schmid J, Förstl H, Perneczky R, Pohl C, Kurtz A (2008) A 6 month, open label study of memantine in patients with frontotemporal dementia. Int $J$ Geriatr Psychiatry 23, 754-759.

[11] Olin JT, Schneider LS, Doody RS, Clark CM, Ferris SH, Morris JC, Reisberg B, Schmitt FA (1996) Clinical evaluation of global change in Alzheimer's disease: identifying consensus. J Geriatr Psychiatry Neurol 9, 176-180.

[12] Boxer AL, Lipton AM, Womack K, Meririlees J, Neuhaus J, Pavlic D, Gandhi A, Red D, Martin-Cook K, Svetilik K, Miller B (2009) An open label of memantine treatment in 3 subtypes of frontotemporal lobar degeneration. Alzheimer Dis Assoc Disord 23, 211-217.

[13] Reisberg B, Doody R, Stöffler A, Schmitt F, Ferris S, Möbius HJ (2003) Memantine in moderate-to-severe Alzheimer's disease. $N$ Engl J Med 348, 1333-1341.

[14] Folstein MF, Folstein SE (1975) A practical method for grading the cognitive state of patients for the clinician. J Psychiatr Res 12, 189-198.

[15] Lebert F, Pasquier F, Souliez, Petit H (1998) Frontotemporal behavioral scale. Alzheimer Dis Assoc Disord 12, 335-339.

[16] Montgomery SA, Asberg M (1979) A new depression scale designed to be sensitive to change. Brit J Psychiatry 134, 382-389.

[17] Kertesz A, Davidson W, Fox H (1997) Frontal behavioral inventory: diagnostic criteria for frontal lobe dementia. Can J Neurol Sci 24, 29-36.

[18] Mattis S (1976) Mental Status Examination for organic mental symptoms in the elderly patient. In Geriatric Psychiatry: A Handbook for Psychiatrists and Primary Care Physicians, Bellak L, Karasu TB, eds, Grune and Stratton, New York, pp. 77-121.

[19] Gélinas I, Gauthier L, McIntyre M, Gauthier S (1999) Development of a functional measure for persons with Alzheimer's dementia: the disability assessment for dementia. Am J Occup Ther 53, 471-481.

[20] Zarit S, Reever K, Bach-Peterson J (1980) Relatives of the impaired elderly: correlates of feelings of burden. Gerolontologist 2, 649-655.

[21] Dubois B, Slachevsky A, Litvan I, Pillon B (2000) The FAB: a frontal assessment battery at bedside. Neurology 55, 16211626.

[22] Marczinski CA, Davidson W, Kertesz A (2004) A longitudinal study of behavior in frontotemporal dementia and primary progressive aphasia. Cogn Behav Neurol 17, 185-190.

[23] Huey ED, Putnam KT, Grafman J (2006) A systematic review of neurotransmitter deficits and treatment in frontotemporal dementia. Neurology 66, 17-22.

[24] Swartz JR, Miller BL, Lesser IM, Darby AL (1997) Frontotemporal dementia: treatment response to serotonin selective reuptake inhibitors. J Clin Psychiatry 58, 212-216. 
[25] Deakin JB, Rahman S, Nestor PJ, Hodges JR, Sahakian BJ (2004) Paroxetine does not improve symptoms and impairs cognition in frontotemporal dementia: a double blind randomized controlled trial. Psychopharmacology (Berl) 172, 400-408.

[26] Lebert F, Stekke W, Hasenbroekx C, Pasquier F (2004) Frontotemporal dementia: a randomised, controlled trial with trazodone. Dement Geriatr Cogn Disord 17, 355-359.

[27] Coull JT, Sahakian BJ, Hodges JR (1996) The alpha (2) antagonist idazoxan remediates certain attentional and executive dysfunction in patients with dementia of frontal type. Psychopharmacology (Berl) 123, 239-249.

[28] Chow TW (2002) Open trial of guanfancine for symptomatic treatment of frontotemporal dementia. J Neuropsychiatry Clin Neurosci 14, 110.
[29] Mendez MF, Shapira JS, McMutray A, Licht E (1997) Preliminary findings: behavioral worsening on donepezil with frontotemporal dementia. Am J Geriat Psychiatry 15, 84-87.

[30] Piguet O, Hornberger M, Shelley BP, Kipps CM, Hodges JR (2009) Sensitivity of current criteria for the diagnosis of behavioral variant frontotemporal dementia. Neurology 72, 732-737.

[31] Knopman DS, Boeve BS, Caselli RJ, Graff-Radford NR, Kramer JH, Mendez MM, Miller BM (2007) Longitudinal tracking of FTLD. Toward developing clinical trial methodology. Alzheimer Dis Assoc Disord 21, S58-S63.

[32] Vossel KA, Miller BL (2008) New approaches to the treatment of frontotemporal lobar degeneration. Curr Opin Neurol 21, 708-716. 